\title{
Penggunaan Bahan Bakar Alternatif dalam Pengelolaan Tambang Batubara sebagai Sumber Energi yang Ramah terhadap Lingkungan
}

\author{
Frances Roi Seston Tampubolon ${ }^{1}$, Arief Sabdo Yuwono², Armansyah Halomoan \\ Tambunan ${ }^{3}$, dan Noer Azam Achsani ${ }^{4}$
}

${ }^{1}$ Natural Resources and Environmental Management, Bogor Agricultural Institute, Indonesia; e-mail: roipb19frances@apps.ipb.ac.id

${ }^{2}$ Department of Civil and Environmental Engineering, IPB University, Bogor, Indonesia

${ }^{3}$ Department of Mechanical and Biosystems Engineering, IPB University, Bogor, Indonesia

${ }^{4}$ School of Business, IPB University, Bogor, Indonesia

\begin{abstract}
ABSTRAK
Penggunaan alternative di masa masa seperti sekarang ini sangat diperlukan. Hal yang paling signfikan adalah penggunaan bahan bakar untuk pengolahan bahan mineral seperti batubara, nikel, tembaga dan lain sebagainya. Dengan penggunaan bahan bakar alternative akan memberikan solusi apabila dibandingkan dengan penggunaan bahan bakar fosil seperti minyak bumi yang sebentar lagi akan mulai habis. Batubara berkontribusi terhadap hujan asam dan kabut asap, terutama ketika dibakar tanpa scrubber. Studi LCA lengkap yang berisi analisis dampak (endpoint impact category) berdasarkan beberapa kategori kesehatan manusia (human health), ekosistem (ecosystem), dan sumber daya air (water resources). Analisis siklus hidup ini dilakukan untuk jenis logam di industri pertambangan. Analisis siklus hidup digunakan untuk menganalisis dampaknya terhadap kesehatan manusia dan pemanasan global. Akan dibutuhkan pengolahan dan penggunaan bahan bakar alternative tersebut sebagai sumber energi. Di dalam penelitian pengolahan data akan sangat dibutuhkan apabila pada saat melihat pengaruh dari penggunaan bahan bakar alternative terhadap kondisi lingkungan yang ada di sekitarnya. Dampak penggunaan listrik yang dikonsumsi untuk proses penambangan akan memberikan pengaruh terhadap meningkatnya efek pada pemanasan global. Fuzzy logic yang akan dikombinasikan dengan penggunaan metode LCA di dalam penelitian ini untuk membantu proses di dalam hal mengumpulkan data menggunakan kuesioner yang dipandu selama fase tujuan dan ruang lingkup (goal and scope) dan analisis persediaan. Selanjutnya metode open LCA untuk melihat hasil yang diperoleh dari data sekunder pada database yang diperoleh sebagai data sekunder. Dari hasil penelitian memberikan nilai 2,5 untuk proses land clearing dan top soil hauling dan nilai 2 untuk over burden stripping nilai 2 over burden disposal, nilai 2 untuk coal hauling dan hasil output memberikan nilai 0,529 untuk global warming potential.
\end{abstract}

Kata kunci: Biodiesel, Alternatif, Pemanasan Global, Konsumsi Energi, Lingkungan

\begin{abstract}
The use of alternatives in times like now is essential. The most significant thing is fuel for processing mineral materials such as coal, nickel, copper, etc. The use of alternative fuels will provide a solution compared to fossil fuels such as petroleum which will soon run out. Coal contributes to acid rain and smog, mostly when burned without a scrubbers. A complete LCA study contains an endpoint impact category based on several human health (ecosystem) categories and water resources. This life cycle analysis is conducted for metal types in the mining industry. It is used to analyze its impact on human health and global warming. It will require processing and use of alternative fuels as an energy source. In research, data processing will be needed when looking at alternative fuels' effects on environmental conditions around it. The impact of the use of electricity consumed for the mining process will impact increasing the effect on global warming. ase goals and scope (goal and scope) and inventory analysis. Furthermore, the open LCA method sees the results obtained from secondary data in the database obtained as secondary data. The results of the study give a value of 2,5 for the land clearing process and top soil hauling and a value of 2 for over burden stripping, a value of 2 for over burden disposal, a value of 2 for coal hauling and the output value gives a value of 0,529 for global warming potential.
\end{abstract}

Keywords: Biodiesel, Alternative, Global warming, Fuel consumption, Environment

Citation: Tampubolon, F.R.S., Yuwono, A.S., Tambunan, A.H., dan Achsani, N.A. (2021). Penggunaan Bahan Bakar Alternatif dalam Pengelolaan Tambang Batubara sebagai Sumber Energi untuk Mengurangi Dampak Terhadap Lingkungan. Jurnal Ilmu Lingkungan, 19(1), 89-97, doi:10.14710/jil.19.1.89-97 
Tampubolon, F.R.S., Yuwono, A.S., Tambunan, A.H., dan Achsani, N.A. (2021). Penggunaan Bahan Bakar Alternatif dalam Pengelolaan Tambang Batubara sebagai Sumber Energi untuk Mengurangi Dampak Terhadap Lingkungan. Jurnal Ilmu Lingkungan, 19(1), 89-97, doi:10.14710/jil.19.1.89-97

\section{Pendahuluan}

Salah satu yang menyebabkan pemanasan global adalah karena pembakaran batubara (Gasparotto \& Martinello, 2020). Batubara berkontribusi terhadap hujan asam dan kabut asap, terutama ketika dibakar tanpa scrubber. Batubara yang terbakar melepaskan bahan kimia beracun dan karbon monoksida yang berkontribusi terhadap penyakit seperti kanker dan asma pada manusia dan hewan liar. Penambangan batubara khususnya penambangan di daerah pegunungan dapat merusak area tanah yang luas dan merusak habitat alami. Selain polusi udara, pembakaran batubara menghasilkan abu batubara beracun, yang dapat menyebabkan polusi air jika secara tidak sengaja maupun akibat dari hasil produksi dan dilepaskan ke lingkungan.

Ada beberapa penelitian yang telah dipublikasikan berdasarkan penilaian siklus hidup dari proses penambangan logam, yang mengukur beban lingkungan yang terkait dengan logam dan sebagian besar studi yang telah dilakukan terutama difokuskan pada penilaian dampak pada pemanasan global, kebutuhan energi, dan potensi keasaman laut. Hanya beberapa studi yang terdiri dari studi Life Cycle Assessment (LCA) lengkap yang berisi analisis dampak (endpoint impact category) berdasarkan beberapa kategori kesehatan manusia (human health), ekosistem (ecosystem), dan sumber daya air (water resources) (Mahmud et al., 2018)(Farjana et al., 2019). Analisis siklus hidup ini dilakukan untuk jenis logam di industri pertambangan. Analisis siklus hidup digunakan untuk menganalisis dampaknya terhadap kesehatan manusia dan pemanasan global. Kebanyakan studi telah dilakukan untuk menganalisis dampak pada lingkungan dan kesehatan manusia (Favi et al., 2016). Dampak penggunaan listrik yang dikonsumsi untuk proses penambangan akan memberikan pengaruh terhadap meningkatnya efek pada pemanasan global. Ada beberapa penelitian lain yang didasarkan pada analisis siklus hidup penambangan batubara untuk melihat dampak lingkungan yang dihasilkan dari kegiatan pertambangan (Talikka, 2020). Analisis dampak lingkungan akan berbeda dan bervariasi untuk lokasi geografis sehingga metode analisisnya akan berbeda juga. Selama ini proses pengelolaan tambang batubara dengan menggunakan bahan bakar fosil seperti minyak bumi, solar atau batubara sudah banyak digunakan (Tayyab et al., 2018). Begitu juga dengan proses pada tahapan hilirisasi dengan menggunakan bahan bakar fosil.

Oleh karena itu dengan melakukan analisa daur siklus hidup penggunaan bahan bakar substitusi akan dilakukan dengan pendekatan seberapa efisienkah penggunaan dari bahan bakar biodiesel (Kung et al., 2013)(J. Jin et al., 2019)(X. Jin et al., 2020). Fuzzy logic yang akan dikombinasikan dengan penggunaan metode LCA di dalam penelitian ini untuk membantu proses di dalam hal mengumpulkan data menggunakan kuesioner yang dipandu selama fase tujuan dan ruang lingkup (goal and scope) dan analisis persediaan (González et al., 2002). Logika fuzzy 90 diterapkan dalam membangun sistem fuzzy dengan membangun hubungan antara data input dan output (Agin et al., 2019). Terobosan tentang model matematika tradisional adalah terletak dimana hubungannya tidak ditentukan oleh persamaan matematika yang kompleks dan dengan menggunakan seperangkat logika aturan dengan menanyakan pendapat seorang ahli (Stettler, 2016). Aturan-aturan ini terdiri dari sebuah antecedent di mana beberapa variabel input dihubungkan dengan cara logis dan konsekuensinya dengan data output (Das et al., 2014). Setelah menetapkan fungsi keanggotaan dan aturan maka inferensi fuzzy proses terjadi dalam beberapa langkah (Dubois \& Prade, 1997). Untuk midpoint impact category dapat terdiri dari Acidification Potential (AP), Ozone Depletion Potential (ODP), Global Warming Potential (GWP) dan Eutrofication Potential (EP).

Definisi dan ruang lingkup tujuan (goal and scope) adalah dapat menentukan sudut pandang dan mengikuti pedoman itu sampai akhir penelitian (Guo et al., 2018). Apabila hasil yang diperoleh telah digunakan selanjutnya adalah hasil tersebut dapat dinyatakan sebagai hasil penelitian dan sesuai dengan tujuan dari kedalaman penelitian dan persyaratan kualitas data yang tetap.

Urutan kegiatan yang akan dilakukan pada analisis pengaruh penggunaan biodiesel sebagai sumber energi pada proses penambangan batubara terhadap dampak lingkungan sepanjang daur hidup (life cycle) (Gan \& Gri, 2018) batubara adalah dengan melakukan langkah langkah yaitu :

1. Identifikasi Analisa

2. Goal dan Scope

3. Membangun Data Inventori Siklus Hidup

4. Mengidentifikasi kategori

5. Kinerja Lingkungan Global dan Regional

6. Penilaian Dampak Siklus Hidup

7. Fuzzy Inference System

8. Indicator Kinerja Lingkungan (rendah, sedang dan tinggi)

Untuk variabel kuantitatif kemudian fungsi keanggotaan didefinisikan sesuai dengan karakter terukur mereka sebagai berikut.

a. Sub kategori

Bobot yang diperoleh tersebut kemudian digunakan dalam konstruksi dasar aturan fuzzy dari mekanisme evaluasi fuzzy.

b. Fuzifikasi

Model Fuzzification Inference System (FIS) yang dikembangkan dalam kerangka yang diusulkan meliputi tiga jenis Member Function (MF) segitiga sesuai dengan masing-masing variabel input. MF ini dibangun berdasarkan yang ditentukan skala target: rendah (L), sedang (M), dan tinggi (H) (JonekKowalska \& Nawrocki, 2019).

\section{c. Rule Base}

Pada bagian selanjutnya kesimpulan output ini dikumpulkan satu sama lain dan membangun satu set fuzzy tunggal. Masukan untuk proses agregasi dikarakterisasi berdasarkan implikasinya proses 
fungsi output. Akhirnya hasil proses agregasi digunakan pada langkah defuzzifikasi.

d. Defuzzification

Dalam langkah ini, lima MF keluaran dirancang itu mentransfer output dari langkah sebelumnya (penilaian fuzzy) ke skala antara 0 dan 1 . MF keluaran ini dinamai rendah (L), medium rendah (LM), sedang $(\mathrm{M})$, sedang-ke-tinggi $(\mathrm{MH})$, dan tinggi $(\mathrm{H})$. Output dari langkah defuzzifikasi memberikan nilai numerik.

Process stages merupakan tahapan yang telah dilakukan di area tambang dengan boundary system yang disajikan pada gambar 1 di bawah ini. Tahapan tersebut adalah :
1. Land Clearing dan Top Soil

2. Top Soil Hauling

3. Over Burden Stripping

4. Over Burden Hauling

5. Over Burden Disposal

6. Coal Blasting

7. Coal Getting

8. Coal Hauling

9. Coal Stockpiling

10. Coal Crusher

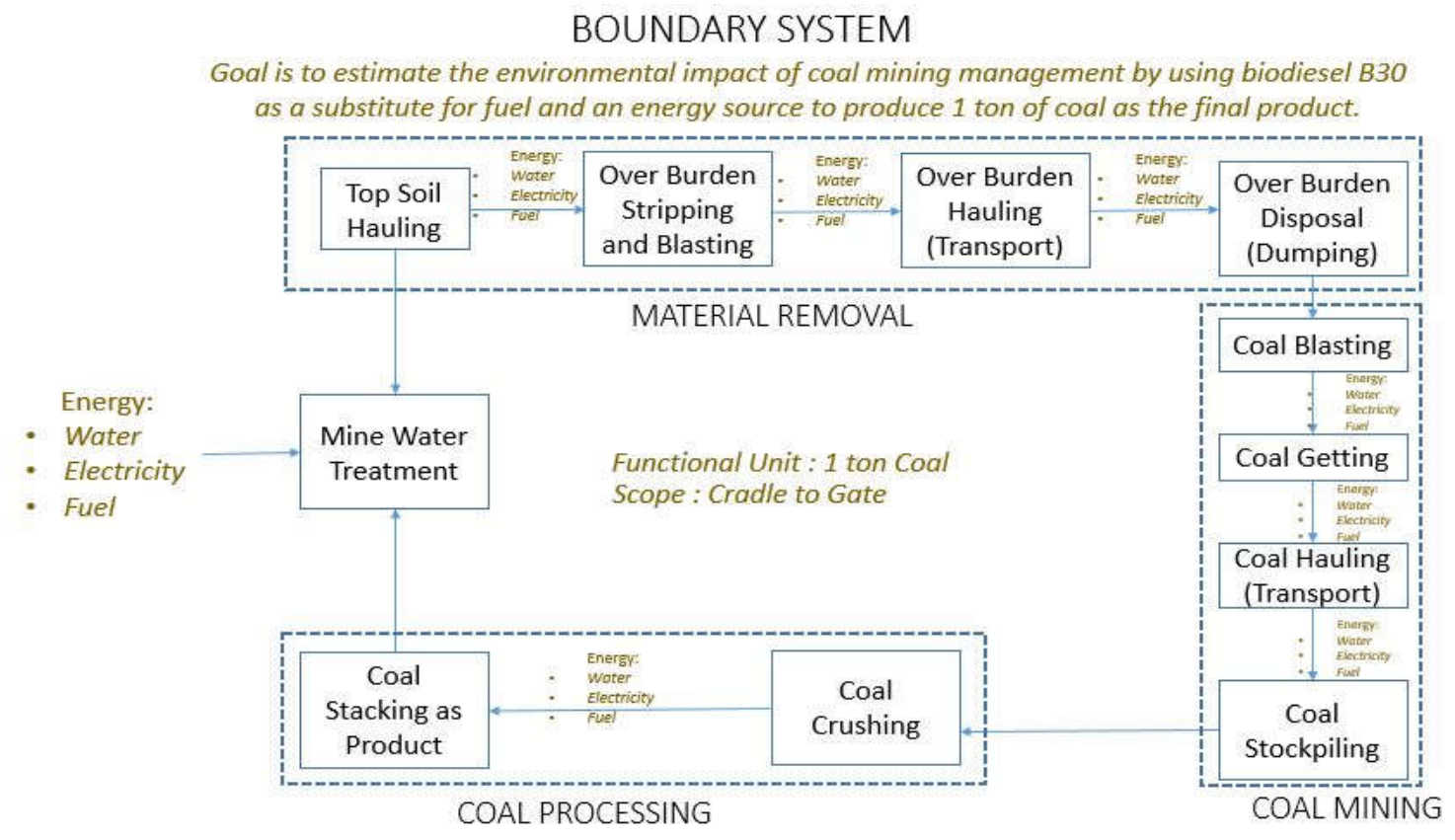

Gambar 1. Diagram Alir Batasan Sistem

\section{Metode}

Metode yang digunakan di dalam penelitian ini menggunakan perangkat lunak open LCA dan metode fuzzy inference system (FIS) untuk melihat nilai hasil dari dampak global GWP dan ODP. Beberapa tahapan yang menjadi analisis di dalam penelitian ini adalah:

1. Land Clearing dan Top Soil Hauling

2. OB Stripping dan OB Hauling

3. OB Disposal, Coal Blasting dan Coal Getting

4. Coal Hauling dan Coal Crusher

Tabel 1. di bawah ini menggambarkan tahapan tersebut.

Tabel 1. Data Fuzzy Set dan Category

\begin{tabular}{lcc}
\hline \hline \multicolumn{1}{c}{ Process Stages (Input) } & Category & Fuzzy Set \\
\hline \multirow{2}{*}{ Land Clearing \& Top Soil } & Low & $(0.5,1.19,2.38)$ \\
Hauling & Medium & $(1.19,2.38,3,58)$ \\
& High & $(2.38,3.58,4.5)$ \\
OB Stripping \& OB Hauling & Low & $(0.5,1.02,2.02)$ \\
& Medium & $(1.02,2.02,3.02)$ \\
& High & $(2.02,3.02,3.5)$ \\
OB Disposal \& Coal Blasting \& & Low & $(0.5,1.02,2.02)$ \\
Coal Getting & Medium & $(1.02,2.02,3.02)$ \\
& High & $(2.02,3.02,3.5)$ \\
Coal Hauling \& Coal Crusher & Low & $(0.5,1.19,2.39)$ \\
& Medium & $(1.19,2.38,3.58)$ \\
& High & $(2.38,3.58,4.5)$ \\
\hline
\end{tabular}

Kemudian selanjutnya global warming potential menggambarkan kontribusi dari tiap proses. Misalnya untuk land clearing dan top soil hauling memberikan kontribusi sebesar $30 \%$ dampak nya terhadap global warming potential. Gambar 2. Dibawah ini menunjukkan kontribusi tiap tahap tersebut.

Dari gambar 2 menunjukkan kontribusi yang paling besar adalah OB disposal dan coal blasting yaitu sebesar 29\%. Pada proses tersebut memang membutuhkan energi yang paling besar di dalam penggunaan bahan bakar di dalam prosesnya. Alat berat menggunakan bahan bakar biodiesel $\left(\mathrm{B}_{30}\right)$ sebagai sumber energi. Untuk memindahkan material OB memang sangat membutuhkan energi yang paling besar. Energi akan membutuhkan bahan bakar biodiesel di dalam prosesnya. Untuk alat berat DT 743 adalah alat dump truck dengan ukuran yang besar akan membutuhkan bahan bakar yang besar juga. Pada saat penggunaan bahan bakar tersebut tentu akan memberikan pengaruh terhadap kondisi lingkungan di area tambang. Kondisi lingkungan yang dimaksud adalah keadaan global warming potential. Kontribusi yang lain memberikan nilai $29 \%$ untuk OBS dan OB hauling kemudian $12 \%$ untuk coal hauling dan coal crusher. 


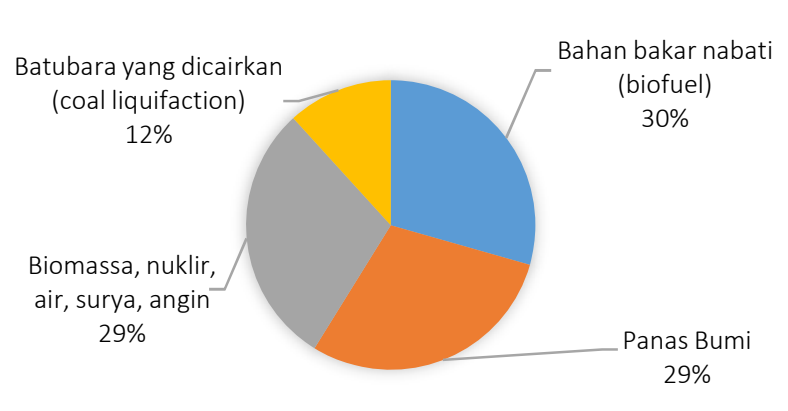

Gambar 2. Process Contribution GWP

Penelitian ini menggunakan metode LCA untuk mengestimasi dampak lingkungan pengelolaan pertambangan batubara dengan menggunakan biodiesel $\left(\mathrm{B}_{30}\right)$ sebagai pengganti bahan bakar dan sumber energi untuk menghasilkan 1 ton batubara (functional unit) sebagai produk akhir. Data base Open LCA digunakan untuk mencapai tujuan 1 dalam penelitian ini seperti yang disajikan pada tabel 2 (IPCC 2012, GWP 100) (US EPA 2018). Metode LCA dilakukan berdasarkan prinsip dan kerangka kerja LCA dalam ISO 14040 (2006). Ini terdiri dari empat tahap, yaitu definisi tujuan dan ruang lingkup (definisi tujuan dan ruang lingkup), analisis persediaan input dan output (analisis inventaris siklus hidup), penilaian dampak lingkungan dari data inventaris (penilaian dampak siklus hidup), dan interpretasi siklus hidup .

Batas sistem akan digunakan dari tujuan yang telah ditentukan dan untuk menentukan ruang lingkup penelitian ini. Prosesnya dimulai dari operasi pengupasan lapisan tanah atas hingga produk akhir batubara. Stok siap pakai dan akan digunakan oleh pengguna batubara dan disebut cradle to gate. Produk batubara yang akan digunakan oleh pengguna (konsumen) adalah PLN, PLTU. Batasan yang telah dibuat akan membatasi bahan baku yang digunakan hingga produk akhir yang dihasilkan.

Data yang telah kita peroleh dan menjadi data persediaan akan difaktorkan menggunakan faktor karakterisasi. Faktor yang diturunkan dari model karakterisasi adalah mengubah hasil inventarisasi siklus hidup menjadi unit umum indikator kategori (SNI ISO 14040: 2016).

Metode FIS akan memberikan hasil dari proses input yang dimasukkan di dalam system. Beberapa input yang dimasukkan akan memberikan kategori di tiap masing masing prosesnya. Data yang dapat dimasukkan sebagai input adalah:

1. Land Clearing dan Top Soil Hauling (LC dan TSH).

2. OB Stripping dan OB Hauling.

3. OB Disposal, Coal Blasting dan Coal Getting.

4. Coal Hauling dan Coal Crusher.

Tabel 2. Data Inventori Penggunaan Bahan Bakar $\mathrm{B}_{30}$ untuk Alat Berat

\begin{tabular}{|c|c|c|c|c|c|c|c|}
\hline $\begin{array}{l}\text { Tahapan } \\
\text { Proses Unit }\end{array}$ & "Unit.No & Liter/HM & $\begin{array}{l}\text { Hour } \\
\text { Metre } \\
(\mathrm{HM}) \\
\end{array}$ & $\begin{array}{c}\text { Konsumsi } \\
\text { Bahan Bakar B } 30\end{array}$ & $\begin{array}{c}\text { Massa jenis } \\
\text { biodiesel } \\
850 \mathrm{~kg} / \mathrm{m}^{3}\end{array}$ & Massa (kg) & $\begin{array}{c}\text { Kalori } \\
1 \mathrm{~kg}=25,37 \times 10^{-6} \mathrm{TJ}\end{array}$ \\
\hline Land & Dozer D10R & 57 & 400 & 136800 & 850 & 116280 & 2.95 \\
\hline $\begin{array}{l}\text { Clearing } \\
\text { dan Top } \\
\text { Soil }\end{array}$ & Excavator PC 320C & 17 & 400 & 40800 & 850 & 34680 & 0.88 \\
\hline Top Soil & Grader & 27 & 400 & 64800 & 850 & 55080 & 1.40 \\
\hline Hauling & DT 740 & 18 & 400 & 43200 & 850 & 36720 & 0.93 \\
\hline OB & DT 741 & 18 & 400 & 43200 & 850 & 36720 & 0.93 \\
\hline Stripping & D6R & 30 & 400 & 72000 & 850 & 61200 & 1.55 \\
\hline (Digging \& & Compactor & 20 & 400 & 48000 & 850 & 40800 & 1.04 \\
\hline Blasting) & Excavator PC 345 & 28 & 400 & 67200 & 850 & 57120 & 1.45 \\
\hline \multirow{4}{*}{ OB Hauling } & D7G & 45 & 400 & 108000 & 850 & 91800 & 2.33 \\
\hline & DT 742 & 18 & 400 & 43200 & 850 & 36720 & 0.93 \\
\hline & Grader & 27 & 400 & 64800 & 850 & 55080 & 1.40 \\
\hline & Excavator PC 375 & 48 & 400 & 115200 & 850 & 97920 & 2.48 \\
\hline \multirow{3}{*}{ OB Disposal } & D7G & 45 & 400 & 108000 & 850 & 91800 & 2.33 \\
\hline & DT 743 & 18 & 400 & 43200 & 850 & 36720 & 0.93 \\
\hline & Compactor & 20 & 400 & 48000 & 850 & 40800 & 1.04 \\
\hline \multirow{3}{*}{$\begin{array}{l}\text { Coal } \\
\text { Blasting }\end{array}$} & DT 743 & 18 & 400 & 43200 & 850 & 36720 & 0.93 \\
\hline & D7G & 45 & 400 & 108000 & 850 & 91800 & 2.33 \\
\hline & Excavator PC 375 & 48 & 400 & 115200 & 850 & 97920 & 2.48 \\
\hline \multirow{4}{*}{ Coal Getting } & Excavator PC 200 & 17 & 400 & 40800 & 850 & 34680 & 0.88 \\
\hline & DT 742 & 18 & 400 & 43200 & 850 & 36720 & 0.93 \\
\hline & Grader & 27 & 400 & 64800 & 850 & 55080 & 1.40 \\
\hline & D7G & 45 & 400 & 108000 & 850 & 91800 & 2.33 \\
\hline Coal & Grader & 27 & 400 & 64800 & 850 & 55080 & 1.40 \\
\hline Hauling & DT 785 & 57 & 400 & 136800 & 850 & 116280 & 2.95 \\
\hline Coal & Grader & 27 & 400 & 64800 & 850 & 55080 & 1.40 \\
\hline Stockpiling & D7G & 45 & 400 & 108000 & 850 & 91800 & 2.33 \\
\hline$(\mathrm{ROM})$ & Compactor & 20 & 400 & 48000 & 850 & 40800 & 1.04 \\
\hline $\begin{array}{l}\text { Coal } \\
\text { Crusher }\end{array}$ & Coal Truck & 18 & 400 & 43200 & 850 & 36720 & 0.93 \\
\hline
\end{tabular}

Tabel 2 di atas menjelaskan seberapa besar bahan bakar yang dipakai pada setiap proses unit yang telah dilakukan. Misalnya adalah pada saat proses land clearing dan top soil menggunakan Dozer D10 R dan excavator PC 320C. Proses ini sangat membutuhkan energi bahan bakar B30 yang besar. 
Untuk menggerakkan alat berat Dozer D10 R tentu saja membutuhkan material yang harus di clearing dalam waktu yang cukup lama. Biasanya proses land clearing membutuhkan 2 hingga 3 hari.

Untuk menentukan besarnya dampak yang diperoleh dari penggunaan bahan bakar dengan menggunakan faktor kategori yang diperoleh dari data IPCC 2012 dan US EPA 2018 sebagai database. Data base yang dipakai adalah menentukan nilai emisi $\mathrm{CO}_{2}$ equivalent dari bahan bakar $\mathrm{B}_{30}$ yang dipakai. Data yang ditampilkan pada tabel 2 di bawah ini dapat juga digunakan untuk menghitung nilai emisi dari kalori yang dihasilkan. Namun database IPCC 2012, GWP 100 juga dapat digunakan untuk mengkonversi jumlah fuel yang diperoleh ke dalam bentuk $\mathrm{kg} \mathrm{CO}_{2}$ eq.

Kombinasi yang dipakai pada kegiatan penambangan batubara akan menjadi hal yang penting di dalam menentukan tahapan proses penambangan batubara. Hal yang paling signifikan adalah untuk menentukan cycle time yang digunakan oleh alat excavator untuk memindakan materlal ke dalam dump truck dan jarak tempuh untuk menjatuhkan material overburden di waste dumping. Cycle time adalah waktu yang dibutuhkan alat berat excavator mulai dari pengambilan material overburden hingga memasukkan material ke dump truck. Apabila jarak tempuh yang diperlukan oleh dump truck untuk menempatkan material sangat dekat tentu saja tidak akan membutuhkan banyak alat berat (dump truck), dan ini akan dapat melakukan penghematan bahan bakar B30.

Untuk hasil akhir adalah memberikan nilai untuk global warming potential (GWP). Hasil akhir memberikan nilai seperti yang ada di dalam gambar 3 di bawah ini:

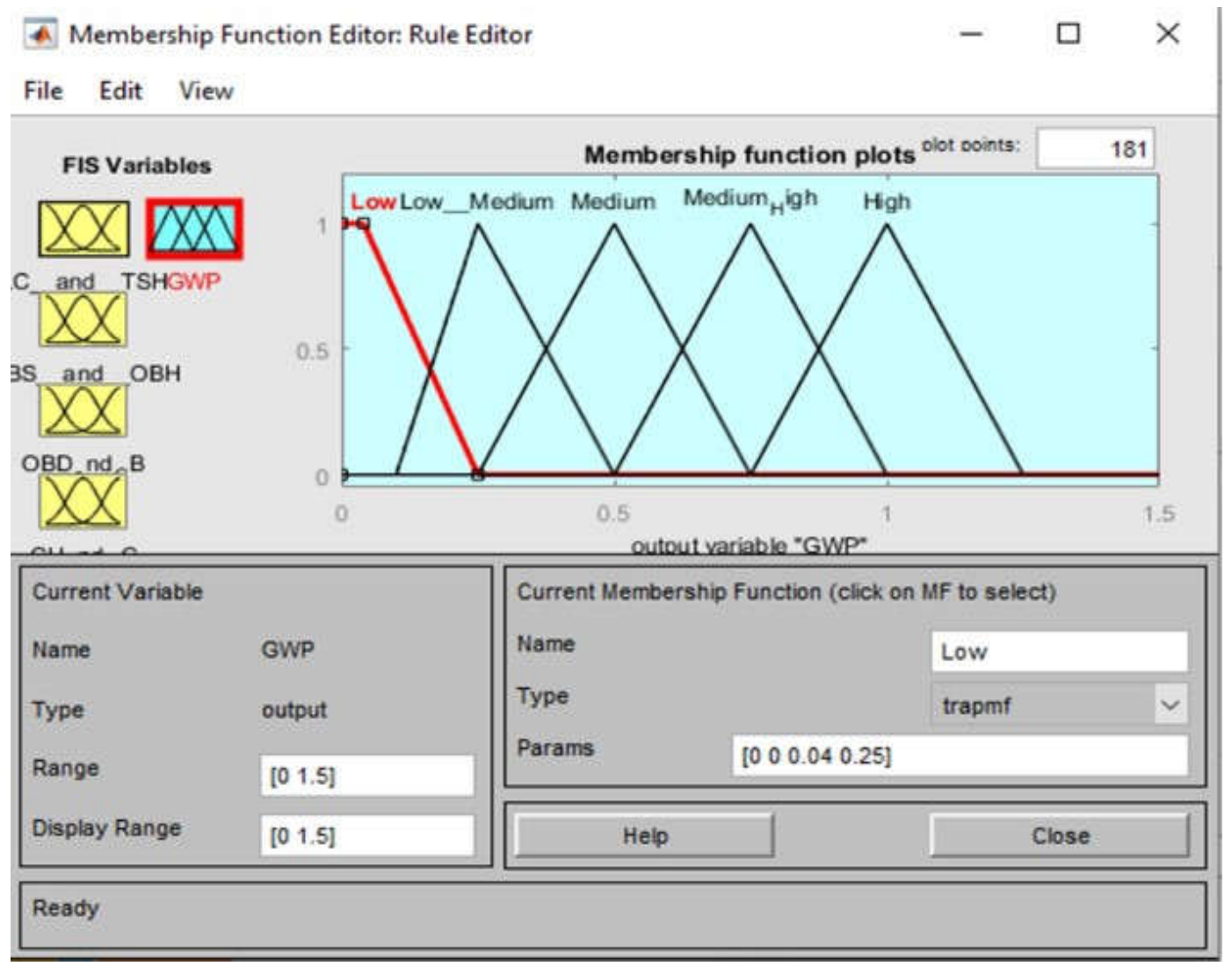

Gambar 3. Membership Function Editor

\subsection{Normalization and Defuzzification}

Metode normalisasi adalah dengan memberikan pembobotan pada nilai GWP dan ODP yang dihasilkan. Untuk menentukan nilai GWP dan ODP tersebut dapat melakukan data yang diberikan dari para pakar (expert) seperti yang disajikan pada tabel 4. Data yang telah diperoleh lalu dimasukkan ke dalam tabel seperti tabel yang ada di bawah ini. Tabel 4 dan tabel 5 di bawah menggambarkan penilaian yang telah diberikan dari data para pakar (expert) di dalam memberikan hubungan kepentingan dari global warming potential (GWP) terhadap Ozon Depletion Potential (ODP). Penilaian kepentingan yang telah diberikan memberikan nilai bahwa GWP lebih penting daripada ODP dan menyatakan dengan nilai $(1.5,2.2 .5)$.

\section{Hasil dan Pembahasan}

Hasil penelitian telah menggambarkan persentasi kontribusi dari penggunaan sumber energi seperti listrik (PLN), material blasting dan sumber bahan bakar biodiesel. Hasil tersebut dapat dilihat dari tabel 3 dibawah ini.

Setelah memasukkan data input yaitu :

1. Land Clearing dan Top Soil Hauling (LC dan TSH).

2. OB Stripping dan OB Hauling.

3. OB Disposal, Coal Blasting dan Coal Getting.

4. Coal Hauling dan Coal Crusher. 
Proses unit land clearing dan top soil hauling memperlihatkan nilai dari emisi yang dihasilkan (Gan \& Gri, 2018). Menurut (Gan \& Gri, 2018) bahwa vegetasi dan tanah dihilangkan untuk mengekspos lapisan bijih. Kemudian emisi GHG (gas rumah kaca) muncul dari dekomposisi mikroba dari biomassa dan tanah yang dihilangkan (degradasi karbon organik tanah). Selain itu produktivitas fotosintesis akan berkurang selama umur tambang karena biomassa yang dihilangkan.. Emisi tersebut merupakan hasil dari penggunaan bahan bakar $\mathrm{B}_{30}$ yang digunakan oleh alat berat yang dipakai di lokasi tambang. Untuk proses unit OB Hauling memberikan hasil yang paling besar dengan nilai persentasi sebesar $16 \%$. Hal ini dikarenakan hampir menggunakan sebagian besar peralatan pada saat penggangkutan material overburden. Pada saat memindahkan material yang akan diangkut oleh dump truk menggunakan bahan bakar yang banyak dan dengan jarak tempuh yang jauh dari lokasi (fleet) penggaliannya (Tsiakmakis et al., 2017). Menurut (Tsiakmakis et al., 2017) inisiatif untuk mengurangi emisi $\mathrm{CO}_{2}$ dari kendaraan ringan telah menjadi landasan kebijakan Eropa membatasi emisi gas rumah kaca transportasi jalan raya.
Rancangan tindakan tersebut terutama didasarkan pada data statistik, alat pemodelan emisi berbasis armada, dan inventaris.

Kemudian beberapa proses unit lain juga hampir memiliki nilai persentasi yang sama besar dengan rata rata di atas $10 \%$ seperti yang disajikan pada tabel $3 \mathrm{di}$ bawah ini. Nilai yang paling kecil adalah pada proses unit coal crusher. Penelitian ini merupakan kombinasi dari metode open LCA dengan metode FIS (fuzzy inference system) yang menggabungkan hasil dari dampak kategori yang dihasilkan kemudian menggunakan metode FIS untuk melihat penilaian dampak kategori yang dihasilkan (Pourjavad \& Mayorga, 2019). Menurut (Pourjavad \& Mayorga, 2019) untuk menggunakan sistem inferensi fuzzy Mamdani, maka harus diterapkan input fuzzy. Pada langkah kedua, untuk mentransfer input yang tajam menjadi input fuzzy, kumpulan input fuzzy diwakili oleh fungsi keanggotaan. Ada beberapa bentuk fungsional dari fungsi keanggotaan untuk menampilkan situasi ketidakjelasan yang berbeda; misalnya bentuk linier, bentuk cekung dan bentuk eksponensial seperti yang disajikan pada gambar $3 \mathrm{di}$ atas.

Tabel 3. Dampak Kategori dari Proses Unit

\begin{tabular}{|c|c|c|c|c|}
\hline \multirow[t]{2}{*}{ No } & \multirow[t]{2}{*}{ Unit Process } & \multirow[t]{2}{*}{ Type of Equipment } & Emissions & \multirow[t]{2}{*}{ Contribution } \\
\hline & & & $\mathrm{kg} \mathrm{CO}_{2}$-eq/ton coal & \\
\hline \multirow{4}{*}{1} & \multirow{4}{*}{ Top Soil } & Dozer $10 \mathrm{R}$ & 2,27 & \multirow{4}{*}{$14 \%$} \\
\hline & & Exc. PC 320 & 0,68 & \\
\hline & & Grader & 1,07 & \\
\hline & & DT 740 & 0,72 & \\
\hline \multirow{4}{*}{2} & \multirow{4}{*}{ OB Stripping } & DT 741 & 0,72 & \multirow{4}{*}{$11 \%$} \\
\hline & & D6R & 1,19 & \\
\hline & & Compactor & 0,80 & \\
\hline & & Exc. PC 345 & 1,11 & \\
\hline \multirow{4}{*}{3} & \multirow{4}{*}{ OB Hauling } & D7G & 1,79 & \multirow{4}{*}{$16 \%$} \\
\hline & & DT 742 & 0,72 & \\
\hline & & Grader & 1,07 & \\
\hline & & Excavator PC 375 & 1,91 & \\
\hline \multirow{3}{*}{4} & \multirow{3}{*}{ OB Disposal } & D7G & 1,79 & \multirow{3}{*}{$10 \%$} \\
\hline & & DT 743 & 0,72 & \\
\hline & & Compactor & 0,80 & \\
\hline \multirow{3}{*}{5} & \multirow{3}{*}{ Coal Blasting } & DT 743 & 0,72 & \multirow{3}{*}{$13 \%$} \\
\hline & & D7G & 1,79 & \\
\hline & & Excavator PC 375 & 1,91 & \\
\hline \multirow{4}{*}{6} & \multirow{4}{*}{ Coal Getting } & Excavator PC 200 & 0,68 & \multirow{4}{*}{$13 \%$} \\
\hline & & DT 742 & 0,72 & \\
\hline & & Grader & 1,07 & \\
\hline & & D7G & 1,79 & \\
\hline \multirow{2}{*}{7} & \multirow{2}{*}{ Coal Hauling } & Grader & 1,07 & \multirow{2}{*}{$10 \%$} \\
\hline & & DT 785 & 2,27 & \\
\hline \multirow{3}{*}{8} & \multirow{3}{*}{ Coal Stockpiling } & Grader & 1,07 & \multirow{3}{*}{$11 \%$} \\
\hline & & D7G & 1,79 & \\
\hline & & Compactor & 0,80 & \\
\hline \multirow[t]{2}{*}{9} & Coal Crusher & Coal Truck & 0,72 & $2 \%$ \\
\hline & & Total & 33,75 & $100 \%$ \\
\hline
\end{tabular}

Tabel 4. Data dari Para Pakar (Expert)

\begin{tabular}{lll}
\hline \hline Variable Linguistik & $\begin{array}{l}\text { Triangular Fuzzy } \\
\text { Numbers }\end{array}$ & Reverse TFN \\
\hline Equally important & $(1,1,1)$ & $(1,1,1)$ \\
A little more & $(1,1.5,2)$ & $(0.5,0.66,1)$ \\
important & $(1.5,2,2.5)$ & $(0.4,0.5,0.66)$ \\
More important & $(2,2.5,3)$ & $(0.33,0.4,0.5)$ \\
Much more & $(0.29,0.33,0.4)$ \\
important & $(2.5,3,3.5)$ & ( \\
\hline
\end{tabular}

Tabel 4 dan tabel 5 menggambarkan penilaian yang telah diberikan dari data para pakar (expert) di dalam memberikan hubungan kepentingan dari global warming potential (GWP) terhadap Ozon Depletion Potential (ODP). Penilaian kepentingan yang telah diberikan memberikan nilai bahwa GWP 
lebih penting daripada ODP dan menyatakan dengan nilai $(1.5,2.2 .5)$.

Maka hasil nilai dari GWP adalah sebesar 0,529 seperti yang disajikan pada gambar 4 . Nilai ini adalah menggambarkan bahwa pengaruh dari penggunaan bahan bakar biodiesel sebagai sumber energi sebesar 0,529 terhadap global warming potential (Ghadimi et al., 2019). Menurut (Ghadimi et al., 2019) dijelaskan bahwa semua hasil didasarkan pada referensi FU listrik $1 \mathrm{~kW}$ jam.
Untuk kasus tersebut penelitian Ghadimi dan kawan kawan menggunakan functional unit (FU) adalah listrik sebesar $1 \mathrm{~kW}$ jam. Hal ini tentu saja berbeda dengan yang ada di penelitian ini yang menggunakan functional unit 1 ton batubara.

Tabel 5. Reverse Triangular Fuzzy Numbers (TFN)

\begin{tabular}{ccc}
\hline \hline Category & GWP & ODP \\
\hline GWP & $1,1,1$ & $1.5,2,2.5$ \\
ODP & $0.4,0.5,0.67$ & $1,1,1$ \\
\hline
\end{tabular}

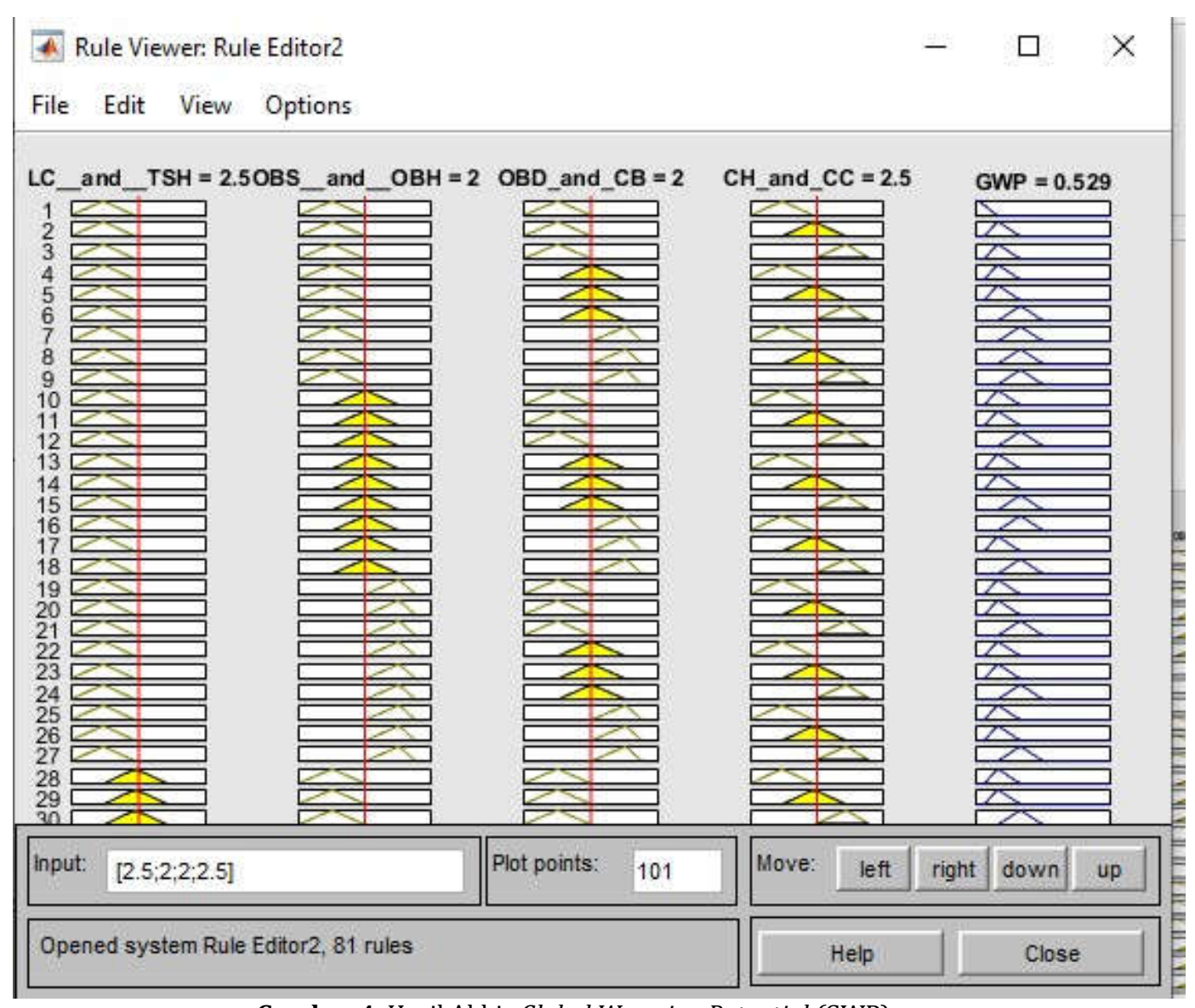

Gambar 4. Hasil Akhir Global Warming Potential (GWP)

Selain itu juga mereka menggunakan lima subkategori telah dipilih, dan Gabi 4's CML 2001 diadaptasi untuk menghitung dampak lingkungan yang terkait dengan sub-kategori ini, yaitu, potensi pengasaman (AP), potensi penipisan ozon (ODP), potensi pemanasan global (GWP), potensi eutrofikasi (EP), dan potensi pembentukan oksidan fotokimia (POCP). Menurut (Gasparotto \& Martinello, 2020) Dampaknya terhadap kesehatan berbeda-beda sesuai dengan komposisi batubara. Setiap lokalisasi global memiliki komposisi batubara yang berbeda sesuai dengan lingkungan pengendapan gambut (H. Dai et al., 2017)(S. Dai et al., 2020). Hal ini tentu tidak digunakan untuk penelitian ini dikarenakan penelitan ini dengan batasan dengan melihat besarnya kategori dampak dari penggunaan bahan bakar $B_{30}$ sebagai sumber energi dan hanya menggunakan impact category GWP dan ODP. Dengan nilai 0,529 tersebut maka dampak terhadap GWP masih dalam kondisi baik (medium). Apabila nilai kinerja yang dihasilkan lebih besar dari 0,5 $(>0,5)$ menunjukkan kondisi yang baik hingga kondisi yang sangat baik terhadap global warming potential. Sebaliknya apabila nilainya $<0,5$ maka kondisinya adalah kurang baik hingga buruk sekali atau nilainya rendah terhadap global warming potential. Penentuan nilai GWP dan ODP adalah dari dari hasil analisis para ahli (expert) yang memberikan penilaian dan dampak yang dihasilkan dari penggunaan bahan bakar $\mathrm{B}_{30}$ seperti yang disajikan pada tabel 4 dan tabel 5 di atas. Kemudian selanjutnya dari data expert maka dilakukan hasil normalisasi dan dampaknya terhadap lingkungan (Stettler, 2016). Hasil yang diperoleh dari para expert kemudian dibandingkan dengan hasil dari kategori dampak yang dihasilkan dari konversi data inventori yang diperoleh di lapangan (Das et al., 2014). Perbandingan ini akan menjadi penilaian akhir seberapa besar perbedaan yang dilakukan oleh para expert dan kemudian dibandingkan dengan impact assessment yang menggunakan aplikasi open LCA seperti yang 
disajikan pada tabel 6 di bawah ini. Dengan hasil sebesar 0,68 atau $68 \%$ adalah hasil yang diperoleh pada kategori dampak sebesar $33,75 \mathrm{~kg} \mathrm{CO}$-eq dan 0,32 atau $32 \%$ adalah hasil yang diperoleh pada kategori dampak untuk Ozon Depletion Potential (ODP).

Tabel 6. Hasil Normalisasi dan Global Environment

\begin{tabular}{cccc}
\hline \hline & Importance FN & Normalisation FN & $\begin{array}{l}\text { Global } \\
\text { Environment }\end{array}$ \\
\hline \multirow{3}{*}{ GWP } & 1.00 & 0.42 & \\
& 1.41 & 0.67 & 0.68 \\
\hline \multirow{3}{*}{ ODP } & 1.58 & 0.97 & \\
& 0.63 & 0.26 & 0.32 \\
\hline
\end{tabular}

\section{Kesimpulan}

Interpretasi menggambarkan nilai dari kinerja GWP dan ODP baik dari metode FIS dan kombinasi dengan opne LCA. Hasil lain juga memberikan kesimpulan dari metode normalisasi dan fuzzification. Metode FIS memperlihatkan hasil kinerja GWP memberikan hasil yaitu 0,529. Kemudian metode normalisasi dan defuzzyfication memberikan hasil berturut turut yaitu GWP 0,68 dan ODP 0,32. Nilai dari 0,68 adalah nilai impact assessment yang diperoleh

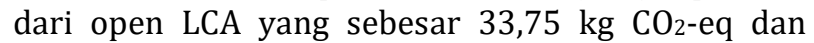
memberikan hasil bahwa kinerja yang dihasilkan dengan menggunakan bahan bakar biodiesel sebagai sumber energi adalah memberikan kontribusi performance sebesar 0,68 (kinerja lingkungan). Artinya nilai tersebut menunjukkan kinerja yang lebih besar memberikan kontribusi kepada global warming potential. Nilai 0,32 memberikan kontribusi sebesar 32 persen pada ODP dari penggunaan bahan bakar biodiesel sebagai sumber energi.

\section{Penghargaan}

Penelitian ini didanai oleh Lembaga Pengelola Dana Pendidikan (LPDP) Kementerian Keuangan Republik Indonesia.

\section{DAFTAR PUSTAKA}

Agin, F., Khosravanian, R., Karimifard, M., and Jahanshahi, A. 2019. Application of Adaptive Neuro-Fuzzy Inference System and Data Mining Approach to Predict Lost Circulation Using DOE Technique (Case Study: Maroon Oilfield ). Petroleum. Pages 1-15.

Dai, H., Yang, H., and Yin, J. 2017. Roles of Energy Conservation and Climate Feedback in Bjerknes Compensation: A Coupled Modeling Study. Climate Dynamics, Vol. 49. Pages 1513.

Dai, S., Hower, J. C., Finkelman, R. B., Graham, I. T., French, D., Ward, C. R., Eskenazy, G., Wei, Q., and Zhao, L. 2020. Organic Associations of Non-Mineral Elements in Coal: A review. International Journal of Coal Geology, Vol. 218. Pages 103347.

Das, B., Ch, S., and Chakrabarty, R. P. 2014. Fuzzy Rule-Based Decision Making to Minimize Wear Rate of Dumper Tires. MSPRO, Vol. 6. Pages 752-761.

Dubois, D., and Prade, H. 1997. Fuzzy Criteria and Fuzzy Rules in Subjective Evaluation :A General Discussion.
Proceedings of 5th European Congress on Intelligent Technologies and Soft Computing. Pages 975-978.

Farjana, S. H., Huda, N., and Mahmud, M. A. P. 2019. Life cycle Assessment of Cobalt Extraction Process. Journal of Sustainable Mining, Vol. 18 No. 3. Pages 150-161.

Favi, C., Germani, M., Mandolini, M., and Marconi, M. 2016. PlantLCA: A Lifecycle Approach to Map and Characterize Resource Consumptions and Environmental Impacts of Manufacturing Plants. Procedia CIRP, Vol. 48. Pages 146-151.

Gan, Y., and Gri, W. M. 2018. Analysis of Life-Cycle GHG Emissions for Iron Ore Mining and Processing in China - Uncertainty and Trends. Vol. 58. Pages 90-96.

Gasparotto, J., and Martinello, K. D. B. 2020. Coal as an Energy Source and Its Impacts on Human Health. Energy Geoscience, Vol. xxxx.

Ghadimi, P., Wang, C., Azadnia, A. H., Lim, M. K., and Sutherland, J. W. 2019. Life Cycle-based Environmental Performance Indicator for the Coal-toEnergy Supply Chain: A Chinese Case Application. Resources, Conservation and Recycling, Vol. 147. Pages 28-38.

González, B., Adenso-Díaz, B., and González-Torre, P. L. 2002. A Fuzzy Logic Approach for the Impact Assessment in LCA. Resources, Conservation and Recycling, Vol. 37 No. 1. Pages 61-79.

Guo, Y., Glad, T., Zhong, Z., He, R., Tian, J., and Chen, L. 2018. Resources, Conservation \& Recycling Environmental Life-Cycle Assessment of Municipal Solid Waste Incineration Stocks in Chinese industrial Parks. Resources, Conservation \& Recycling, Vol. 139. Pages 387-395.

Jin, J., Wan, X., Lin, Y., Kuang, F., and Ning, J. 2019. Public Willingness to Pay for the Research and Development of Solar Energy in Beijing, China. Energy Policy, Vol. 134. Pages 110962.

Jin, X., Li, X., Feng, Z., Wu, J., and Wu, K. 2020. Linking Ecological Efficiency and the Economic Agglomeration of China based on the Ecological Footprint and Nighttime Light Data. Ecological Indicators, Vol. 111. Pages 106035.

Jonek-Kowalska, I., and Nawrocki, T. L. 2019. Holistic Fuzzy Evaluation of Operational Risk in Polish Mining Enterprises in a Long-Term and Sectoral Research Perspective. Resources Policy, Vol. 63. Pages 101464.

Kung, C. C., McCarl, B., Cao, X., and Xie, H. 2013. Bioenergy Prospects in Taiwan Using Set-Aside Land-An Economic Evaluation. China Agricultural Economic Review, Vol. 5 No. 4. Pages 489-511.

Mahmud, M. A. P., Huda, N., Farjana, S. H., and Lang, C. 2018. Environmental Impacts of Solar-Photovoltaic and Solar-Thermal Systems with Life-Cycle Assessment. Energies, Vol. 11 No. 9.

Pourjavad, E., and Mayorga, R. V. 2019. A Comparative Study and Measuring Performance of Manufacturing Systems with Mamdani Fuzzy Inference System. Journal of Intelligent Manufacturing, Vol. 30 No. 3. Pages 1085-1097.

Stettler, C. 2016. Global Impacts and Local Limits of Ecosystems - Combining Fuzzy Logic with Global Impacts and Local Limits of Ecosystems - Combining Fuzzy Logic with LCA Event Introduction Hydro Power : Global versus local / regional impacts Fuzzy Set Theory ( FST ) Mode. October.

Talikka, M. 2020. Geometallurgy: A Key to Optimizing the Mining Value Chain Key Take Aways.

Tayyab, M., Noman, A., Islam, W., Waheed, S., Arafat, Y., Ali, F., Zaynab, M., Lin, S., Zhang, H., and Lin, W. 2018. 
Bioethanol production from lignocellulosic biomass by Environment-Friendly Pretreatment Methods: A Review. Applied Ecology and Environmental Research, Vol. 16 No. 1. Pages 225-249.

Tsiakmakis, S., Fontaras, G., Anagnostopoulos, K., Ciuffo, B., and Marotta, A. 2017. A Simulation based Approach for Quantifying $\mathrm{CO}_{2}$ Emissions of light Duty Vehicle Fleets. A case study on WLTP introduction. Transportation Research Procedia, Vol. 25. Pages 3898-3908. 